\title{
Reflexiones en torno \\ a la contaminación del medio ambiente andino
}

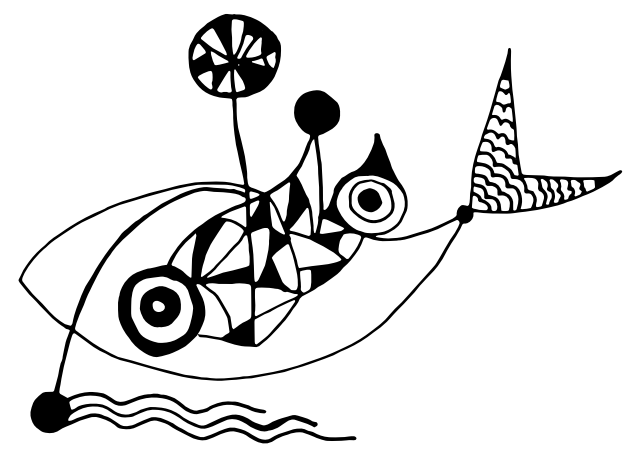

Por Mario Mejía Huamán

\section{Justificación de la ponencia}

El filósofo latinoamericano Leopoldo Zea sugería que los latinos debíamos filosofar sobre el hombre y sus problemas fundamentales. En tal sentido, consideramos que la contaminación del medio ambiente andino es un peligro no solo para los Andes sino para toda la humanidad.

\section{Informe sobre los ingresos económicos por concepto de explotación minera en el Perú}

Para tener un concepto sobre los ingresos económicos generados por la explotación de los minerales en el Perú vamos a presentes algunas informaciones al respecto. En la dirección electrónica, abajo citada, aparece el siguiente titular: "Producción de oro en Perú se incrementa 5,09\% durante marzo del 2012".

En comparación a la cifra del mismo mes del 2011, según informó el Ministerio de Energía y Minas (MEM). "La producción de oro en marzo de 2012 fue de 13'757.863 gramos finos y en el mismo mes de 2011 fue de 13'091.570 gramos finos. El salto más espectacular en producción de oro de la última década ha tenido lugar en Indonesia que ha aumentado su producción desde las 2 toneladas que extraía en 1992 a las 167 extraidas en el 2005, procedentes principalmente de la mina Grasberg,

$1 \mathrm{http} / /$ www.americaeconomia.com/negocios-industrias/produccion-de-oro-enperu-se-incrementa-5.09-durante-marzo la más grande del mundo. Asimismo el Perú ha experimentado un gran avance ya que durante el mismo periodo ha pasado de 18 a 207 toneladas, de las cuales la mitad procede de Yanacocha, la segunda mina de oro más grande del mundo."

Otra información afirma que las Reservas Internacionales Peruanas aumentan a USD \$ 57.490 millones $^{3}$. Según reportó el $\mathrm{BCR}^{4}$ (Banco Central de Reserva), el crecimiento de las RIN en abril -del 2012-favorece el blindaje de nuestra economía ${ }^{5}$.

Seguidamente tenemos una tercera información que manifiesta que las "Empresas mineras ganaron más de US\$ 5,000 millones" "y que "Southern" fue una de las empresas que más utilidades tuvo".

Ahora bien, nos preguntamos ¿qué hace el Perú con los 57,490 millones de Reservas Internacionales? La

2 Ministerio del Ambiente - MINAM Correo: webmaster@minam.gob.pe Sábado 5 de mayo del 2012 23:25 Economia. El subrayado es nuestro.

326 de junio del 2012.

4 http://elcomercio.pe/tag/40834/bcr

5 http://elcomercio.peleconomia/1410951/noticia-reservas-internacionalesperuanas-aumentan-us57490-millones. (Andina). Las Reservas Internacionales Netas (RIN) del Perú aumentaron a 57.490 millones de dólares al cierre de abril del presente año, mayor en 1.701 millones respecto a marzo, lo que favorece un adecuado blindaje a nuestra economía, señaló hoy el $B C R$.

6 http://www.larepublica.pe/25-05-2012/empresas-mineras-ganaronmás-de-us-5-000-millones

7 Grupo México (Grupo México S.A. de C.V.), es la compañía minera más grande de México y la tercera productora de cobre más grande del mundo. es.wikipedia.org/wiki/Southern_Perú_Copper_Corporation 
respuesta es que el gobierno peruano prefiere tenerlos guardados en las bóvedas de los bancos, mientras las provincias en cuyo subsuelo se encuentran las minas más ricas del mundo, como Yanacocha, tiene a su población en extrema pobreza, faltan centros de trabajo, puestos asistenciales de salud, alto porcentaje de analfabetismo, desnutrición crónica. Donde el estado no garantiza, la vivienda, salud, trabajo y seguridad; donde el sueldo de los médicos, profesores y policías al servicio del Estado no exceden los \$ 500 USD.

Por otro lado, en el último año, 2011-2012, el Perú tiene problemas con la población de las zonas mineras ya que las empresas extractoras lo hacen sin el menor cuidado del medio ambiente. A dicho problema se suma que el gobernante actual, cuando fue candidato, mostró su acuerdo con la voluntad del pueblo, de preferir "el agua al oro", pero una vez en el poder hace lo contario.

\section{Contraste entre los departamentos mineros y su realidad social}

Justamente, en los departamentos de Cajamarca, Huancavelica, Apurímac y Cuzco, en que se explotan oro, plata y otros metales, existe extrema pobreza ${ }^{8}$.

La provincia de Cajamarca del Departamento del mismo nombre tiene $34.3 \%$ de desnutrición crónica. Gualgayoc, donde se encuentra la mina Conga: de 44.4 $\%$ a $47.7 \%$. En diez años de explotación del oro en el departamento de Cajamarca, la provincia en cuyo subsuelo se encuentra uno de los yacimientos auríferos más grandes del mundo, no ha podido superar el grado de desnutrición crónica, escolaridad, analfabetismo, problema de ocupación, asistencia médica. Cajamarca es una zona agrícola-ganadera, sin embargo, el Índice de Desarrollo Humano en la provincia solo alcanza el 47 \% y en Gualgayoc 45 \%. La Población Económicamente Activa en ambas provincias alcanza apenas el $44.7 \%$. En las provincias de Cajamarca y Gualgayoc 2,579 familias no envían a sus hijos a la escuela. La tasa de población analfabeta mayor de 15 años llega al 54.7 $\%$ en las dos provincias.

Huancavelica, otro departamento minero importante del Perú, tiene una alto porcentaje de analfabetismo. En Angaráes el $39 \%$ de la población no sabe leer ni escribir, porcentaje que se eleva casi al $50 \%$ en el Área rural. ${ }^{9}$

\footnotetext{
8 http://sinia.minam.gob.pe/index.phaccion=verMapa\&idElemento Informacion=1043\&idformula = Fuente de Información Ministerio del Ambiente - MINAM Correo: webmaster@minam.gob.pe

$9 \quad$ Ibidem, pág. 28
}

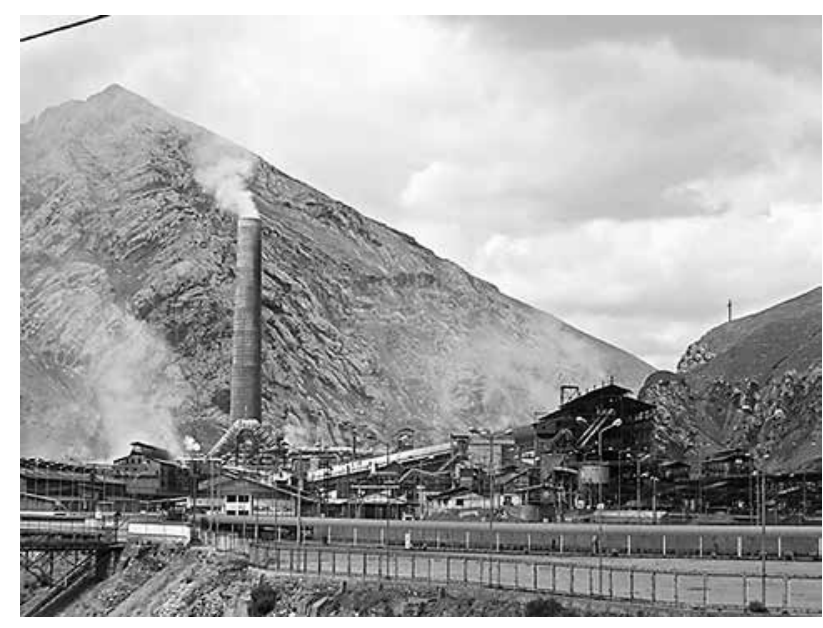

Huancavelica tiene un altísimo porcentaje de niños con desnutrición crónica, que en el ámbito rural de la provincia de Angaráes se eleva a un pavoroso 65,3 \% ${ }^{10}$

El índice de desarrollo humano del programa de Naciones Unidas para el Desarrollo coloca a Huancavelica en el penúltimo lugar entre los departamentos peruanos. ${ }^{11}$ Por lo expuesto, podemos sostener que la provincia más deprimida de Huancavelica es Angaráes, con el puesto 192 de índice de desarrollo humano entre las 194 provincias peruanas. ${ }^{12}$ Una mujer de Huancavelica tiene una esperanza de vida menor en doce años al promedio peruano. Esta cifra grafica de manera impresionante las grandes desigualdades del Perú. ${ }^{13}$

El Cuzco, donde se encuentra una de las Maravillas del Mundo: Machu Picchu, la provincia de Chumbivilcas ostenta uno de los índices más altos de ruralidad del Perú: 86,80 \% ${ }^{14}$. "Mientras la provincia del Cuzco figura en el undécimo lugar en índice de desarrollo humano en el Perú, las de Paruro y Paucartambo ocupan el puesto 182 y 186 respectivamente. ${ }^{15}$ Algunos indicadores demográficos del departamento son todavía muy preocupantes. Así, la tasa de mortalidad infantil se eleva a 73 por mil." 16

En Apurímac, según el índice elaborado en el año 2000, por el Programa de la Naciones Unidas para el Desarrollo (PNUD), la provincia minera de Cotabambas se encontraba en el penúltimo lugar (193) en la escala de desarrollo humano; y en cuanto al ingreso familiar per cápita, las provincias de Chincheros, Ayma-

10 Ibidem, pág. 29

11 Ob. Cit., pág. 31

12 Ob. Cit., pág. 31

13 Ob. Cit., pág. 33

14 Diario La República, Atlas Departamental del Perú, Cuzco, Apurímac. Pág. 37.

15 Ob. Cit. Pág. 42

16 Ob. Cit. Pág. 43 


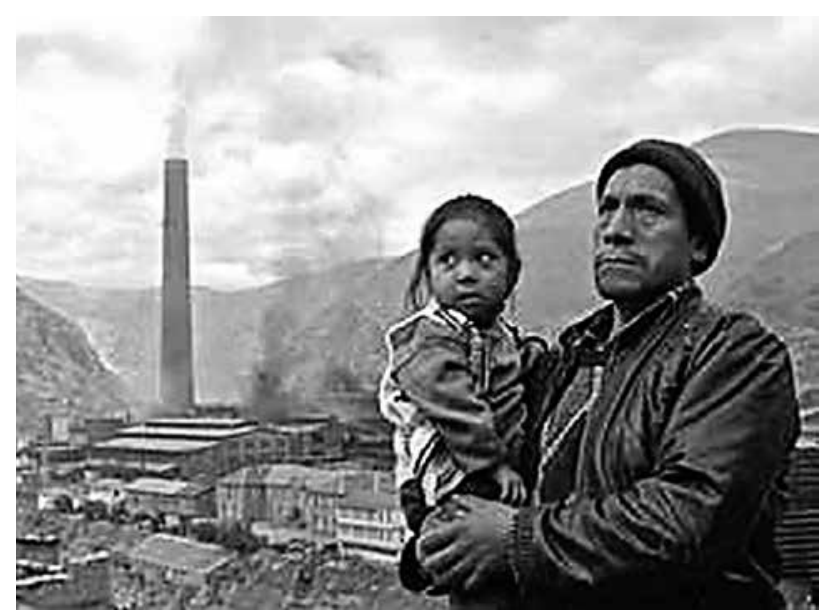

ráes, Grau y Cotabambas ocupaban los cuatro últimos lugares (191 a 194). La Encuesta Nacional de Hogares del 2001, elaborada por el INEI (Instituto Nacional de Estadística e Información) atribuye al departamento de Apurímac un $78 \%$ de pobres, de los cuales $47 \%$ están en situación de extrema pobreza. En el departamento de Apurímac se dan los más altos índices de desnutrición en el área rural, especialmente entre los varones. La provincia de Cotabambas es la que registra el índice más alto con un alarmante 56,6 \%. En forma coincidente, la misma provincia presenta una tasa de analfabetismo del 51,9\%. El departamento registra índices por debajo del promedio nacional en la cobertura de Servicios Básicos ${ }^{17}$.

Para finalizar, consideramos que transcurridos los cincuenta años que en Yanacocha y otras provincias se explota el oro, los millones de dólares recibidos por el Perú por concepto de canon minero no resolverán la desnutrición crónica, el analfabetismo, la desocupación, la carencia de puestos de salud, de hospitales, de agua potable. Los niños continuarán caminando descalzos; la contaminación ambiental habrá afectado los ríos, como el Amazonas, y los lagos; los campos de cultivo se habrán desertificado, los habitantes se habrán debilitado y empobrecido al extremo.

\section{El "waki", paradigma de una distribución más justa}

Nuestra propuesta, dirigida a nivel de Estado Peruano, que bien podría valer para toda Sudamérica y los continentes en vías de desarrollo, es:

1. Las comunidades deben ser dueñas del suelo y subsuelo en que residen, de manera que ellas deben decidir si explotan o no sus riquezas, además de señalar la manera de cómo se debe explotar ${ }^{18}$.

2. Las naciones dueñas de materias primas no deberían permitir que los bienes se sigan explotando a la manera capitalista individualista sino a la manera colectivista, de modo que la riqueza beneficie en $50 \%$ a los países dueños de las riquezas y en $50 \%$ a las empresas transnacionales.

Finalmente, si el gobierno peruano tuviera sensibilidad social los US\$ 57.490 millones de Reservas internacionales ${ }^{19}$ no estarían durmiendo en los Bancos. Si como consigna la información de que los más de US\$ 5, 000 millones que ganaron las Empresas mineras ${ }^{20}$, el 50 por ciento perteneciera por el waki ${ }^{21}$ al Perú, la realidad sería otra.

Felizmente, la concepción del mundo está cambiando y como tal podemos volver a sentir que, tal como pensaban nuestros antepasados, la naturaleza tiene vida. Nosotros en la modernidad la hemos tratado como objeto que se compra y se vende y la hemos estado matando sin pensar que su muerte también será la nuestra. La naturaleza no es, pues, un objeto al que podemos tratarla como una mercancía. Hoy, no hay duda de que al cuidarla estamos también cuidando nuestra vida, la de nuestros hijos y la de todos los seres animados que en ella habitan.
17 El popular, Atlas Regiones del Perú. Huancavelica. Geografía, historia, cultura, turismo. 2004. Ediciones PEISA S.A.C., págs., 28 al 30.
18 En el caso peruano el Artículo Art. 54 de la Constitución Política determina que: "El territorio del Estado es inalienable e inviolable. Comprende el suelo, el subsuelo, el dominio marítimo, y el espacio aéreo que cubre". Nueva Constitución Politica del Perú. Aprobada por el Congreso Constituyente Democrático del Perú (CCD) Ratificada en el Referéndum del 31-10-93 y Promulgada el 29 de diciembre de 1993.

1926 de junio del 2012.

20 http://www.larepublica.pe/25-05-2012/empresas-mineras-ganaronmas-de-us-5-000-millones

21 El waki es un sistema de explotación agrícola ancestral andino y consiste en que el fruto de la cosecha es repartida en partes iguales entre el labrador y el dueño de la tierra de cultivo. 